\title{
CORRIGENDUM
}

\section{Analysis of IgH translocations, chromosome 13q14 and 17p13.1(p53) deletions by fluorescence in situ hybridization in Waldenstrom's macroglobulinemia: a single center study of 22 cases}

H Chang, S Samiee, D Li, B Patterson, Cl Chen and A Keith Stewart

Leukemia (2004) 18, 1564. doi:10.1038/sj.leu.2403456

Correction to: Leukemia (2004) 18, 1160-1162.

doi:10.1038/sj.leu.2403369
The authors have identified that the name of the co-author A Keith Stewart was mis-spelled in the above article. The correct name is reproduced below:

\section{AK Stewart}

The authors apologize for any confusion this might have caused. 